\title{
Research
}

\section{The effect of strength training on muscle cellular stress in prostate cancer patients on ADT}

\author{
T S Nilsen', L Thorsen'2, C Kirkegaard', I Ugelstad', S D Fosså2 and T Raastad' \\ 'Department of Physical Performance, Norwegian School of Sports Sciences, Oslo, Norway, \\ ${ }^{2}$ Department of Oncology, Oslo University Hospital, Oslo, Norway
}

\begin{abstract}
Background: Androgen deprivation therapy (ADT) for prostate cancer (PCa) is associated with several side effects, including loss of muscle mass. Muscle atrophy is associated with reduced mitochondrial function and increased muscle cellular stress that may be counteracted by strength training. Thus, the aim of this study was to investigate the effect of strength training on mitochondrial proteins and indicators of muscle cellular stress in PCa patients on ADT.

Methods: Men diagnosed with locally advanced PCa receiving ADT were randomised to a strength training group (STG) $(n=16)$ or a control group (CG) $(n=15)$ for 16 weeks. Muscle biopsies were collected pre- and post-intervention from the vastus lateralis muscle, and analysed for mitochondrial proteins (citrate synthase, cytochrome c oxidase subunit IV (COXIV), HSP60) and indicators of muscle cellular stress (heat shock protein (HSP) 70, alpha B-crystallin, HSP27, free ubiquitin, and total ubiquitinated proteins) using Western blot and ELISA.

Results: No significant intervention effects were observed in any of the mitochondrial proteins or indicators of muscle cellular stress. However, within-group analysis revealed that the level of HSP70 was reduced in the STG and a tendency towards a reduction in citrate synthase levels was observed in the CG. Levels of total ubiquitinated proteins were unchanged in both groups.

Conclusion: Although reduced HSP70 levels indicated reduced muscle cellular stress in the STG, the lack of an intervention effect precluded any clear conclusions.
\end{abstract}

Correspondence should be addressed to T S Nilsen Email t.s.nilsen@nih.no
Endocrine Connections (2016) 5, 74-82

\section{Introduction}

Prostate cancer (PCa) patients with locally advanced disease are often treated with androgen deprivation therapy (ADT) to prevent tumour progression (1). Loss of skeletal muscle mass is a common side effect of ADT $(2,3,4)$, which in turn might lead to reduced muscular strength and endurance $(5,6)$. Effective interventions to prevent impairments in muscle function during ADT are therefore needed.
Castration is associated with impaired mitochondrial function (7). As mitochondrial dysfunction is involved in muscle protein degradation, this might be one of the mechanisms behind ADT-induced loss of muscle mass $(8,9)$. In skeletal muscle, the ubiquitin proteasome system is one of the major sites for protein breakdown, where E3 ligases promote ubiquitin conjugation of proteins destined for breakdown by the 26 s proteasome (10). 
Removal of testosterone has been shown to increase the expression of muscle-specific E3 ligases (11), and this may also play a role in ADT-induced loss of muscle mass. Strength training, however, has been shown to increase the activity of mitochondrial proteins in elderly men $(12,13)$. Therefore, strength training may be an effective strategy against muscle loss in PCa patients on ADT.

Heat shock proteins (HSPs) are molecular chaperons, essential for proper protein folding of newly synthesized proteins (14) and refolding of denatured proteins in order to prevent aggregation (15). HSP70, HSP27 and alpha B-crystallin have important roles in reinforcing the cytoskeleton (16). Thus, HSPs might prevent denaturation and may even refold denatured proteins before they irreversibly aggregate and are ultimately metabolized via proteolytic pathways (17). Consequently, the content of HSPs is increased when muscle cells are exposed to several types of stressors $(18,19)$ and increasing age, at least for the larger HSPs (20). This would, in theory, preserve muscle mass, by stabilisation of stressed and damaged proteins (21). No studies to date have investigated the effect of strength training on HSPs in PCa patients on ADT.

Although ADT may induce severe side effects on the muscle cellular level, and strength training has the potential to counteract this, no studies to date have addressed this in humans. Therefore, the aim of this exploratory study was to investigate the effect of strength training in PCa patients on ADT, on mitochondrial proteins and indicators of muscle cellular stress. We expected that strength training would increase levels of mitochondrial proteins and decrease levels of HSP and proteins marked for degradation through ubiquitination.

\section{Materials and methods}

This study was conducted as a part of the Physical Exercise and Prostate Cancer (PEPC) trial. All subjects gave their written consent to participate in the study, which conformed to the Declaration of Helsinki. The Regional Committee for Medical and Health Research Ethics, Southeast Region approved the study (protocol nr. 08/212b.2008/4062), and the trial is registered at ClinicalTrials.gov (NCT00658229). Rationale and design of this two-armed randomised controlled trial are published elsewhere (22). In short, newly diagnosed PCa patients of intermediate- or high-risk profile on (neo)-adjuvant ADT, 75 years old or younger, were invited. The exclusion criteria were routinely performing strength training,

http://www.endocrineconnections.org DOI: 10.1530/EC-15-0120 receiving medication for osteoporosis, or suffering from any conditions that could complicate strength training.

\section{Design and randomisation}

The baseline biopsy was obtained at least 1 month after radiotherapy, corresponding to 5 months or more after initiation of ADT depending on the duration of the neoadjuvant part of ADT. Thereafter, the ADT-treated PCa patients were randomly assigned, in the ratio $1: 1$, to a strength training group (STG) or a control group (CG) for 16 weeks, when the post-biopsy was obtained.

\section{Strength training program}

The strength training program was performed 3 times a week for 16 weeks during ongoing ADT. The training sessions progressed from one to three sets throughout the period and included nine exercises: Smith machine half squat, leg press, smith machine standing calf raise, knee flexion, knee extension, chest press, seated row, shoulder press and biceps curl. The first 2 weeks were used for light-intensity familiarisation. Thereafter, the training load was 10 RM (maximum load that can be repeated 10 times) on Mondays and 6 RM on Fridays. On Wednesdays, a submaximal session was performed with a resistance equivalent to $80-90 \%$ of the patient's 10 RM load in 10 repetitions. All high-load sessions were performed under supervision. Patients in the CG were encouraged to maintain their current habitual activity level.

\section{Assessments}

All muscle biopsies were obtained the week before and after the intervention. Importantly, to exclude the effect of the last training session in the analysis, all postintervention biopsies were obtained 72 or $96 \mathrm{~h}$ after the last training session in the STG.

\section{Muscle biopsy procedures and homogenisation}

The muscle biopsies were collected from the mid part of the vastus lateralis muscle, separated by at least $3 \mathrm{~cm}$ to avoid any repeated biopsy effect. After injection of local anaesthetic, Xylocain-epinephrine $10 \mathrm{mg} / \mathrm{mL}+5 \mu \mathrm{g} / \mathrm{mL}$ (AstraZeneca, Södertälje, Sweden) and sterilisation of the surface, a $1-2 \mathrm{~cm}$ incision was made in the skin and the fascia of the vastus lateralis muscle. The biopsies were 
Table 1 Overview of antibodies used in this study.

HSP70
Alpha B-crystalline
HSP27
HSP27
HSP60
COXIV
Citrate synthase
Ubiquitin

\begin{tabular}{l}
\hline Cat. no. \\
\hline ADI-SPA-810 \\
ADI-SPA-222 \\
ADI-SPA-800 \\
ADI-SPA-803 \\
SPA-807-E \\
Ab14744 \\
ab96600 \\
SPA-203
\end{tabular}

\begin{tabular}{l}
\hline LOT \\
\hline 12071118 \\
9011032 \\
9061109 \\
3020917 \\
12409 \\
GR67749-1 \\
GR134613-9 \\
B405440
\end{tabular}

\begin{tabular}{l} 
Most \\
\hline Mouse \\
Mouse \\
Rabbit \\
Mouse \\
Mouse \\
Rabbit \\
Mouse
\end{tabular}

$1: 4000$

$1: 4000$

$1: 10,000$

$1: 10,000$

$1: 4000$

$1: 1000$

$1: 12,000$

$1: 2000$

Manufacturer
Enzo Life Sciences (Farmingdale, NY, USA)
Enzo Life Sciences (Farmingdale, NY, USA)
Enzo Life Sciences (Farmingdale, NY, USA)
Enzo Life Sciences (Farmingdale, NY, USA)
Stressgen Biotechnologies (Victoria, BC, Canada)
Abcam (UK)
Abcam (UK)
Nordic Biosite AB (Täby, Sweden)

obtained using a 6-mm Pelomi needle (Albertslund, Denmark; the Bergström technique) and manual suction. Pieces for immunoassays were rinsed in ice cold saline (0.9\% NaCl; Braun, Melsungen, Germany) and carefully dissected free of visual fat, connective tissue and blood. Pieces of $50 \mathrm{mg}$ were frozen in isopentane on dry ice and stored at $-80^{\circ} \mathrm{C}$ for later homogenisation.

Total protein was extracted from muscle samples using a commercially available kit (T-PER Tissue Protein Extraction Reagent, cat. no. 78510; Thermo Fisher Scientific) according to the manufacturer's procedures. Furthermore, 2\% protease and phosphatase inhibitor cocktail (Halt Protease and Phosphatase Inhibitor Cocktail, cat. no. 78440, Thermo Fisher Scientific) and 2\% EDTA were added to the lysate dilution according to the manufacturer's procedures.

As the above-described method discards the cytoskeleton fraction of the homogenate, a second muscle sample was fractionated into a cytosol, membrane, cytoskeletal, and nuclear fraction using a commercially available fractionation kit (ProteoExtract Subcellular Proteome Extraction Kit, cat. no. 539790, Calbiochem, EMD Millipore, Darmstadt, Germany) according to the manufacturer's procedures.

Protein concentrations were determined using a commercial kit (BioRad DC Protein micro plate assay, cat. nos 0113, 0114 and 0115, Bio-Rad), a filter photometer (Expert 96, ASYS Hitech, Cambridge, UK) and the provided software (Kim, ver. 5.45.0.1, Daniel Kittrich, Prague, Czech Republic). $\gamma$-globulin was used as a standard protein, ranging from 0.125 to $1.5 \mathrm{mg} / \mathrm{mL}$. Protein standard curve and samples were analysed in triplicate; standard curve: $r^{2}>0.9$.

\section{Western blot}

Equal amount of protein (10-40 $\mu$ g per well, depending on the fraction loaded) was loaded and separated by precast NuPAGE Novex 4-12\% Bis-tris Midi gels (cat. no. NP0321, Invitrogen) for 35-45 $\mathrm{min}$ at $200 \mathrm{~V}$ in cold MES running buffer (NuPAGE MES SDS Running Buffer, cat. no. NP0002, Life Technologies, Invitrogen). All subcellular fractions and time points were routinely loaded on the same gel to enable comparison. Separated proteins were transferred onto immune-blot PVDF membrane (Immuno-blot, cat. no. 162-0177, Bio-Rad) at $30 \mathrm{~V}$ for $90 \mathrm{~min}$ in cold transfer buffer (NuPAGE Transfer Buffer, cat. no. NP0006-1, Life Technologies, Invitrogen). Whereas membranes used for HSP70 and alpha B-crystallin (Table 1) were blocked overnight at $4^{\circ} \mathrm{C}$ in a $5 \%$ fat-free skimmed milk and $0.05 \%$ TBS-Tween solution (TBS, cat. no. 170-6435, BioRad; Tween 20, cat. no. 437082Q, VWR International, Radnor, PA, USA; Skim milk, cat. no. 1.15363, Merck). Membranes used for HSP60, cytochrome c oxidase subunit IV (COXIV), citrate synthase, free ubiquitin and total ubiquitinated proteins (Table 1) were blocked at room temperature (RT) for $2 \mathrm{~h}$. Blocked membranes were then incubated with monoclonal primary antibodies for $2 \mathrm{~h}$ at RT or overnight at $4^{\circ} \mathrm{C}$. Thereafter, membranes were incubated with secondary antibody (goat anti-mouse, cat. no. 31430, Thermo Fisher Scientific/Pierce Biotechnology) diluted 1:30,000 or 1:2000 (anti-rabbit IgG, cat. no. 7074, Cell Signalling) at RT for $1 \mathrm{~h}$. All antibodies were diluted in a $1 \%$ fat-free skimmed milk and $0.05 \%$ TBS-Tween solution. Between stages, the membranes were washed with $0.05 \%$ TBS-Tween. Protein bands were visualised, with horseradish peroxidase (HRP) detection system (Super Signal West Dura Extended Duration Substrate, cat. no. 34076, Thermo Fisher Scientific/Pierce Biotechnology). Chemiluminescence was measured using a CCD image sensor (Kodak Image Station 2000R, Eastman Kodak company, Rochester, NY, USA), and band intensity was calculated using the Carestream Molecular Imaging software (v. 5.0.7.2.2., Carestream Health, New Haven, CT, USA). All samples were analysed in duplicate, and mean values were used for statistical analysis. Representative blots are listed in Fig. 1, and blots for free ubiquitin and total ubiquitinated proteins in Fig. 2.

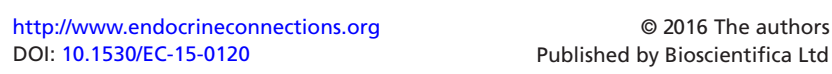


Pre Post Pre Post Pre Post Pre Post

Citrate synthase
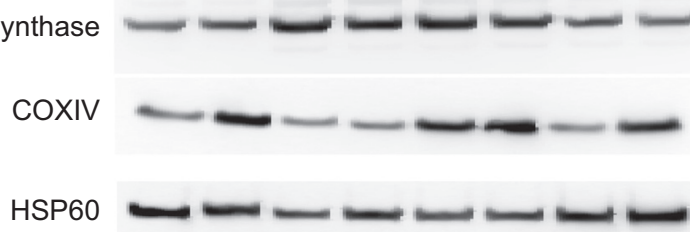

HSP70

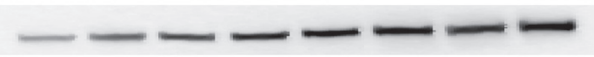

AlphaB-crystallin

\section{Figure 1}

Representative blots for citrate synthase, COXIV, HSP60, HSP70 and alpha B-crystallin.

\section{Enzyme-linked immunosorbent assay}

Protein quantification of HSP27 was performed using a double-antibody sandwich ELISA developed within our laboratory.Eachsubcellularfraction wasanalysedseparately and later combined to give the total cellular amount. A monoclonal capture antibody against HSP27 (25 ng per well; mouse anti-HSP27 (Enzo Life Sciences, Farmingdale, NY, USA)) and a polyclonal detection antibody against HSP27 (rabbit anti-HSP27 (Enzo Life Sciences)) was diluted 1:10,000 and HRP conjugate was used as secondary antibody, diluted 1:10,000 (Amersham Biosciences; GE

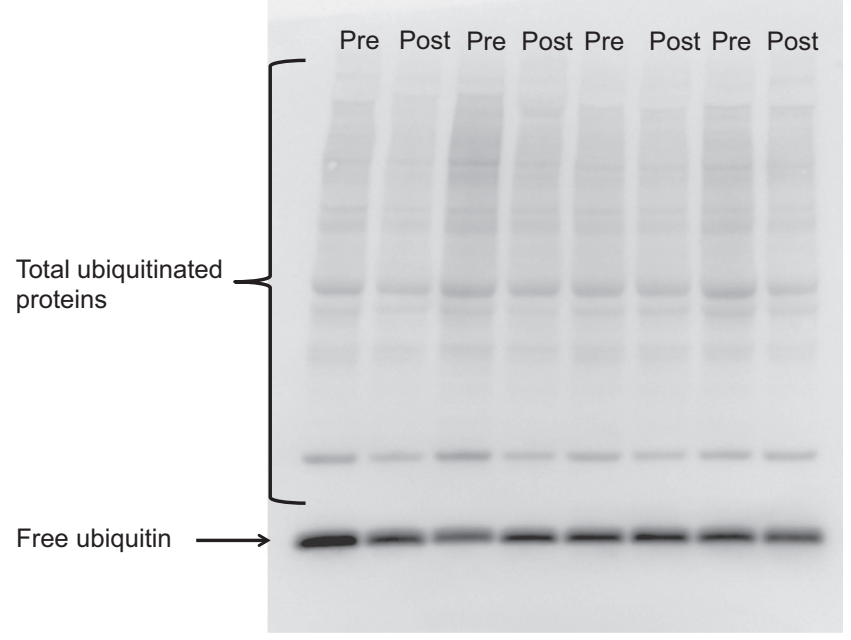

Figure 2

Representative blots for total ubiquitinated proteins and free ubiquitin.

Healthcare Life Sciences, Buckinghamshire, UK). The HSP27 assay was performed in high-binding polystyrene microplates (Costar 3590, Costar, Inc., Corning, NY, USA) using tetramethylbenzidine (TMB Solution, Calbiochem, EMD Biosciences) as substrate, and $1 \mathrm{M}$ sulphuric acid as stop solution. Recombinant HSP27 (Enzo Life Sciences) was used as standards (0.0975-25 ng/mL). All samples were diluted 1:300 (cytosolic fraction), 1:100 (membrane fraction) or 1:50 (cytoskeletal fraction) and

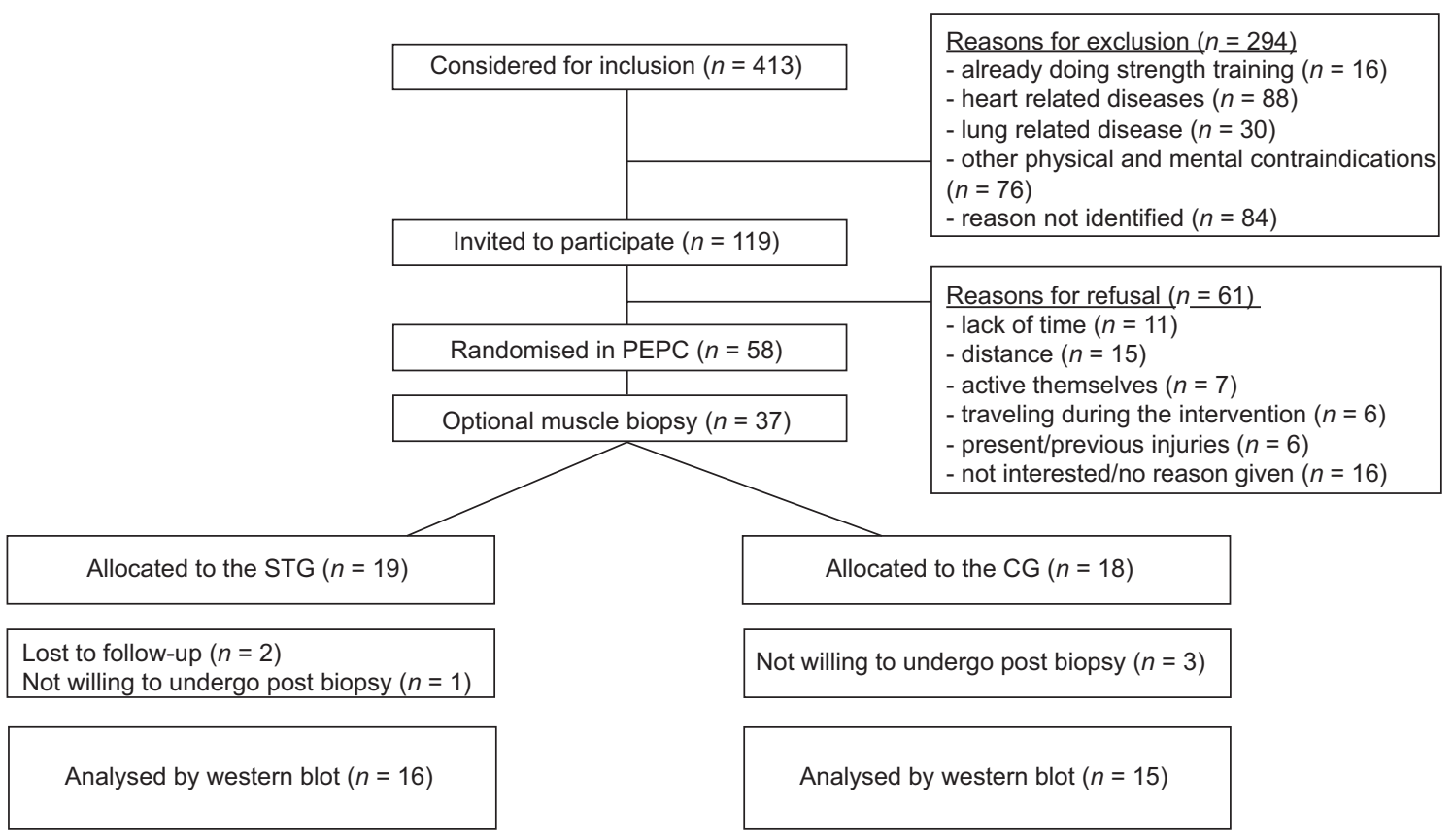

Figure 3

Consort diagram.

$\begin{array}{lr}\text { http://www.endocrineconnections.org } & \text { ○ } 2016 \text { The authors } \\ \text { DOI: } 10.1530 / \text { EC-15-0120 } & \text { Published by Bioscientifica Ltd }\end{array}$


Table 2 Baseline characteristics.

\begin{tabular}{|c|c|c|}
\hline & STG $(n=16)$ & CG $(n=15)$ \\
\hline \multicolumn{3}{|l|}{ Age (years) } \\
\hline Mean (range) & $66(54-76)$ & $65(54-76)$ \\
\hline S.D. & 6 & 5 \\
\hline \multicolumn{3}{|l|}{ Height (m) } \\
\hline Mean & $\begin{array}{l}1.78 \\
(1.70-1.87)\end{array}$ & $\begin{array}{l}1.75 \\
(1.52-1.88)\end{array}$ \\
\hline S.D. & 0.1 & 0.1 \\
\hline \multicolumn{3}{|l|}{ Weight (kg) } \\
\hline Mean & $\begin{array}{l}90.3 \\
(75.1-114.6)\end{array}$ & $\begin{array}{l}89.8 \\
(70.9-118.3)\end{array}$ \\
\hline S.D. & 10.8 & 14.2 \\
\hline \multicolumn{3}{|l|}{ Body mass index $\left(\mathrm{kg} / \mathrm{m}^{2}\right)$} \\
\hline Mean & $\begin{array}{l}28.6 \\
(24.1-38.9)\end{array}$ & $\begin{array}{l}29.2 \\
(25.0-35.8)\end{array}$ \\
\hline S.D. & 3.5 & 3.2 \\
\hline \multicolumn{3}{|l|}{ Risk profile groups } \\
\hline $\begin{array}{l}\text { Intermediate (proportion of } \\
\text { patients) }\end{array}$ & 43 & 33 \\
\hline High (proportion of patients) & 56 & 67 \\
\hline \multicolumn{3}{|l|}{$\begin{array}{l}\text { Time on ADT at baseline } \\
\text { (months) }\end{array}$} \\
\hline Mean (range) & $9.2(7-12)$ & $9.3(6-12)$ \\
\hline S.D. & 1.7 & 1.9 \\
\hline \multicolumn{3}{|l|}{ Total time on ADT (months) } \\
\hline Mean (range) & $18.0(8-28)$ & $20.5(8-28)$ \\
\hline S.D. & 8.5 & 8.3 \\
\hline \multicolumn{3}{|l|}{$\begin{array}{l}\text { Time from rad. to baseline } \\
\text { (months) }\end{array}$} \\
\hline Mean (range) & $3.0(1.2-6.6)$ & $2.8(0.7-5.8)$ \\
\hline S.D. & 1.4 & 1.3 \\
\hline \multicolumn{3}{|l|}{$\begin{array}{l}\text { Testosterone at baseline } \\
(\mathrm{mmol} / \mathrm{L})\end{array}$} \\
\hline Mean (range) & $\begin{array}{l}0.56 \\
(<0.40-1.50)\end{array}$ & $\begin{array}{l}0.65 \\
(<0.40-1.30)\end{array}$ \\
\hline S.D. & 0.27 & 0.26 \\
\hline
\end{tabular}

S.D., standard deviation; BMI, body mass index; ADT, androgen deprivation therapy; rad, radiotherapy.

analysed in triplicate $(\mathrm{CV}<10 \%)$. The amount of HSP27 was determined using a filter photometer measuring optical density at $450 \mathrm{~nm}$.

\section{Statistics}

Only patients with both baseline and post-biopsies were included in the analysis. Normality was assessed by visual inspection of plots as well as D'Agostino-Pearson omnibus normality test. Data that passed the normality test were analysed by comparing the mean change between groups by the two-sample $t$-test, and data that failed the normality test (COXIV and total ubiquitinated proteins) were analysed by a nonparametric Wilcoxon matched-pairs signed-rank test. Within-group changes are visualised in graphs by individual relative changes, and within-group mean changes and 95\% CIs. Extreme outliers were identified using Bland-Altman plots and removed from the data set. Removal of outliers did not alter any between or within-group changes. Data were analysed using GraphPad Prism 5 (version 5; GraphPad Software, Inc., http://www.graphpad.com).

\section{Results}

\section{Baseline characteristics}

Between 2009 and 2011, 104 eligible patients were invited to the PEPC trial and 58 agreed to participate. Of these, 37 patients were willing to undergo muscle biopsies at baseline, of which two patients dropped out due to accidents not related to the study and four refused to undergo postbiopsies due to discomfort. This resulted in 16 patients in the STG and 15 patients in the CG (Fig. 3). At baseline, the mean duration of ADT (LHRH analogue) was 9 months; other baseline characteristics are listed in Table 2.

\section{Mitochondrial proteins}

There was no difference in mean change in the levels of citrate synthase (STG: $0.5 \pm 19.0 \%, \mathrm{CG}:-5.1 \pm 10.3 \%, P=0.35$ )

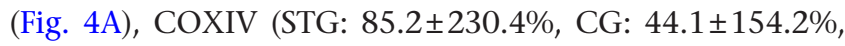
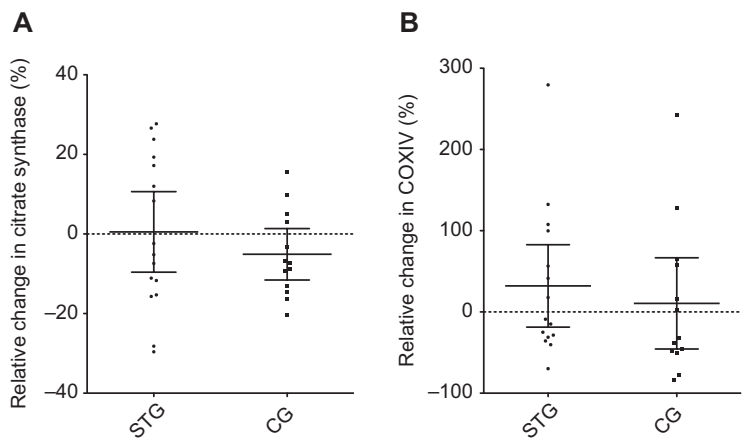

http://www.endocrineconnections.org DOI: 10.1530/EC-15-0120
C

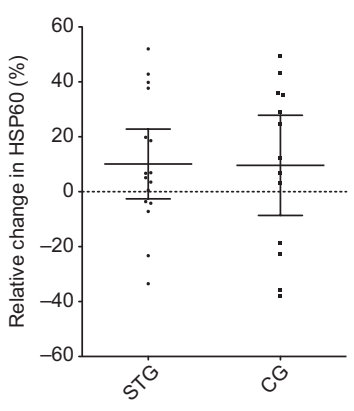

Figure 4

Relative change in citrate synthase (A), COXIV (B) and HSP60 (C). Values are expressed as individual change from baseline to post-assessment. Bars represent group mean and $95 \%$ confidence intervals. 


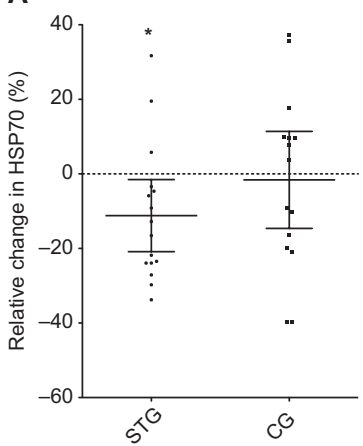

B

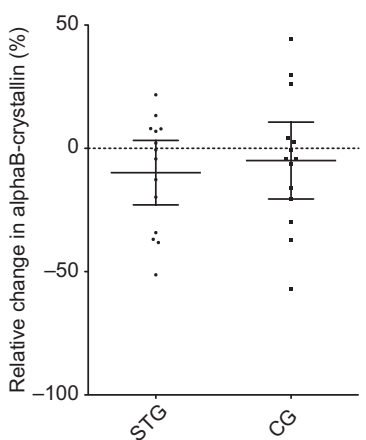

C

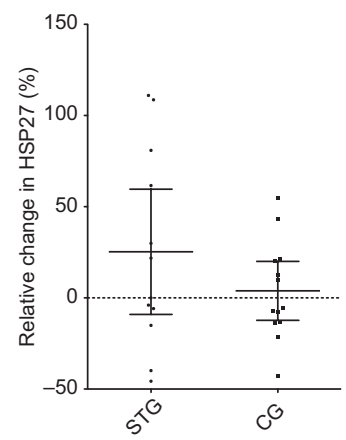

Figure 5

Relative change in HSP70 (A), alpha B-crystallin (B) and HSP27 (C). Values are expressed as individual change from baseline to postassessment. Bars represent group mean and 95\% confidence intervals.
$P=0.58$ ) (Fig. 4B) or HSP60 (STG: 9.9 $\pm 24.0 \%$, CG: $9.8 \pm 29.9 \%, P=0.98$ ) (Fig. 4 C) between the groups during the intervention. There was, however, a weak tendency towards a reduction in citrate synthase within the CG $(-5.1 \pm 10.3 \%, P=0.09)$ (Fig. 4 A).

\section{Indicators of muscle cellular stress}

There was no difference in mean change between the STG and the CG in HSP70 (STG: $-11.2 \pm 18.1 \%$, CG: $-1.6 \pm 23.5 \%$, $P=0.20$ ) during the intervention period (Fig. 5A). Also, there was no difference in mean change for the small HSPs: alpha B-crystallin (STG: $-9.9 \pm 22.6 \%$, CG: $-5.0 \pm 27.0 \%$, $P=0.60$ ) (Fig. 5B) and HSP27 (STG: 66.5 $\pm 888.4 \%$, CG: $-6.1 \pm 843.4 \%, P=0.62$ ) (Fig. 5C). HSP70 was, however, significantly reduced within the STG $(P=0.03)$ (Fig. 5A). There was no difference in mean change in free ubiquitin (STG: $8.4 \pm 49.9 \%$, CG: $-13.6 \pm 20.2 \%, P=0.16$ ) (Fig. 6 A) or in total ubiquitinated proteins (STG: $34.8 \pm 77.6 \%$, CG: $26.0 \pm 68.7 \%, P=0.77$ ) (Fig. 6B) between the STG and the CG. No within-group changes were observed for any group.
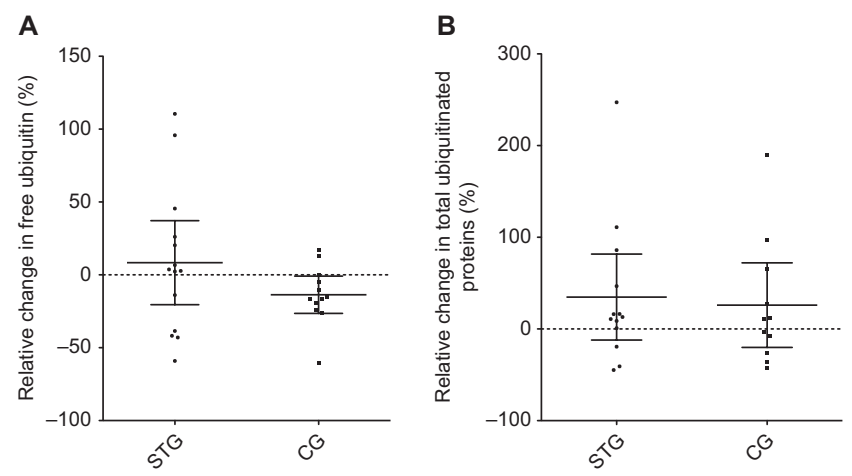

Figure 6

Relative change in free ubiquitin (A) and ubiquitinated proteins (B). Values are expressed as individual change from baseline to postassessment. Bars represent group mean and $95 \%$ confidence intervals.

\section{Discussion}

This is the first study to evaluate the effect of strength training on mitochondrial proteins and indicators of muscle cellular stress in PCa patients on ADT. Contrary to our expectations, no effect of the intervention was observed in the levels of mitochondrial proteins, HSPs or ubiquitin or ubiquitinated proteins. We did, however, observe decreased levels of HSP70 within the STG from baseline to post-intervention.

The lack of change in mitochondrial proteins in this study is in contrast to studies in elderly men, where strength training has been show to increase the activity of mitochondrial proteins $(12,13)$. Increases have even been reported from strength training in men suffering from mitochondrial myopathies (23). As opposed to the above-cited studies, we measured the content of several mitochondrial proteins rather than enzyme activity per se. However, mitochondrial enzymatic activity has been shown to be reliant upon the total amount of enzymes $(24,25)$, and the content of citrate synthase and COXIV is shown to be a reliable marker of mitochondrial content in skeletal muscle $(26,27)$. Interestingly, castration decreases the activity of COXIV, and testosterone supplementation increases the enzymatic activity (7). Therefore, the testosterone-suppressed status of the PCa patients in this study may have reduced the mitochondrial adaptation to strength training.

Our Western blot results were normalized to the total amount of protein in each sample. We have previously reported increased muscle fibre area of type II fibres $(P=$ 0.03 ) in the PEPC trial (28). Thus, type II fibres are most likely accounting for a larger amount of the total protein content in the post-biopsy compared with the baseline biopsy. This could further explain the lack of increases in mitochondrial proteins in this study, because type I fibres contain a greater mitochondrial mass than type II fibres (29). In addition, when both fibre types were

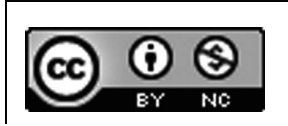

This work is licensed under a Creative Commons Attribution-NonCommercial 4.0 International License. 
combined, there was a tendency towards an increased muscle fibre cross-sectional area $(P=0.09)$ within the STG in the PEPC trial (28). Therefore, our results indicate an increase in the absolute mitochondrial mass because our Western blots are normalised to the total protein content, and we report unchanged concentration of mitochondrial proteins.

There were no group differences in mean change in any of the HSPs. However, as expected, we observed reduced levels of HSP70 within the STG. It has been shown that strength training increases the levels of both HSP70 and alpha B-crystallin in young healthy men (16), and training-induced HSP response seems to be dependent upon training intensity $(30,31)$. However, all heavy training sessions in the PEPC trial were performed under the supervision of an exercise physiologist to ensure sufficient training intensity. Therefore, we do not suspect that low training intensity could explain the HSP results in this study. However, there are indications in the literature that basal levels of HSPs are elevated in aged muscle compared with younger muscle $(20,32)$. Thus, we suspect that the HSP levels are already elevated at baseline in this study, especially because the PCa patients had been on ADT for 9 months prior to our baseline assessment. Thus, reduced levels of HSPs may indicate a normalisation of the cellular environment.

Moreover, castration has been shown to blunt the normal HSP70 response in cardiac muscle during endurance exercise in rodents (33). Interestingly, when the castrated rats were supplemented with DHT, a testosterone metabolite, there was no difference in the HSP70 response compared with intact rats (33). Also, some synthetic anabolic steroids have been shown to increase HSP levels in skeletal muscle (34). Therefore, androgens seem to play a role in mediating the HSP levels in men, and possibly also the response to exercise. However, the effects of ADT on HSP levels in human skeletal muscle are not known, and we cannot rule out that baseline levels of HSPs in this study were different from healthy subjects.

We did not observe any effect of strength training on the levels of free ubiquitin or ubiquitinated proteins in this study. There are a limited number of studies exploring the levels of ubiquitin in skeletal muscle in the literature; however, elevated levels of ubiquitinated skeletal muscle proteins have been observed after heart failure in rats, and aerobic exercise decreased these levels (35). Tendencies towards elevated levels of ubiquitinated muscle proteins were also observed in heart failure patients compared with healthy controls, and aerobic exercise led to nonsignificant reductions (35). To our knowledge, no previous study has investigated the effect of strength training, or testosterone suppression, on the levels ubiquitinated muscle proteins. However, testosterone suppression has been shown to increase the expression of Murf-1 and Atrogin-1 (11), which in theory would lead to increased ubiquitination of muscle proteins. Nevertheless, if strength training induces similar effect as described previously for endurance training, testosterone suppression seems to hamper this effect during ADT.

This study suffers from limitations that need to be taken into account, before the results can be generalized. First, our baseline biopsy was obtained 6-12 months after commencing ADT; thus, our results may not represent events occurring immediately after commencing ADT. Second, the sample population available for analysis in this study was of relatively small size, which may have introduced statistical type 2 errors. Therefore, the results of this study must be interpreted with caution. Third, of the 119 patients invited to participate, only 58 patients agreed to participate, of which 37 patients agreed to undergo the muscle biopsy procedure (Fig. 3). Therefore, the overall external validity of the study may be questioned. However, this study still provides novel insight into the effects of strength training during ADT, and also highlights the importance of expanding the current knowledge on the muscular side effects of longterm ADT.

In sum, in this study, we observed no intervention effects on mitochondrial proteins and indicators of muscle cellular stress. This was contrary to our expectations and contrary to studies in healthy elderly. Importantly, we report no change in the concentration of mitochondrial enzymes, meaning that the absolute levels most likely are increased. Furthermore, reduced levels of HSP70 were observed within the STG following the intervention, and we speculate that this may be an indicator of a stabilisation of the cellular environment. Future studies should compare exercise effects on the muscle cellular level between patients on and off ADT; in addition, future studies should also investigate the effects of different antiandrogen treatment options on the muscle cellular level.

\section{Declaration of interest}

The authors declare that there is no conflict of interest that could be perceived as prejudicing the impartiality of the research reported.

\section{Funding}

The PEPC trial was supported by the Norwegian Foundation of Health and Rehabilitation and the Norwegian Cancer Society (HF-57004/001) and
This work is licensed under a Creative Commons Attribution-NonCommercial 4.0 International License. 
co-funded by the Regional Health Authority in southern Norway. Additional funding was also given by Eckbo's legacy, the Radium Hospital's legacy and Trivselsanlegget's legacy.

\section{Acknowledgements}

The authors thank all patients for participating, and Melanie-Birte Schulz, Stine Solli, Siri Kjellaas, Jon Reidar Iversen, Nils K. Raabe, Kjell Magne Russnes and Gunnar Tafjord for their help with identifying and including patients. They also thank the Department for Clinical Research Support, Oslo University Hospital, Oslo, Norway, for their assistance with tasks related to the data management of this study.

\section{References}

1 Sharifi N, Gulley JL \& Dahut WL. Androgen deprivation therapy for prostate cancer. JAMA 2005294 238-244. (doi:10.1001/ jama.294.2.238)

2 Smith MR. Changes in body composition during hormona therapy for prostate cancer. Clinical Prostate Cancer 20032 18-21. (doi:10.3816/CGC.2003.n.008)

3 Boxer RS, Kenny AM \& Taxel P. The effect of 6 months of androgen deprivation therapy on muscle and fat mass in men with prostate cancer. Journal of the American Geriatrics Society 200553 S71-S72.

4 van Londen GJ, Levy ME, Perera S, Nelson JB \& Greenspan SL. Body composition changes during androgen deprivation therapy for prostate cancer: a 2-year prospective study. Critical Reviews in Oncology/Hematology 200868 172-177. (doi:10.1016/j. critrevonc.2008.06.006)

5 Clay CA, Perera S, Wagner JM, Miller ME, Nelson JB \& Greenspan SL. Physical function in men with prostate cancer on androgen deprivation therapy. Physical Therapy 200787 1325-1333.

6 Galvao DA, Taaffe DR, Spry N, Joseph D, Turner D \& Newton RU. Reduced muscle strength and functional performance in men with prostate cancer undergoing androgen suppression: a comprehensive cross-sectional investigation. Prostate Cancer and Prostatic Diseases 200912 198-203. (doi:10.1038/pcan.2008.51)

7 Koenig H, Goldstone A \& Lu CY. Androgens regulate mitochondrial cytochrome c oxidase and lysosomal hydrolases in mouse skeletal muscle. Biochemical Journal 1980192 349-353. (doi:10.1042/ bj1920349)

8 Jezek P \& Hlavata L. Mitochondria in homeostasis of reactive oxygen species in cell, tissues, and organism. International Journal of Biochemistry \& Cell Biology 200537 2478-2503.

9 Romanello V \& Sandri M. Mitochondrial biogenesis and fragmentation as regulators of muscle protein degradation. Current Hypertension Reports 201012 433-439. (doi:10.1007/s11906-010-0157-8)

10 Wing SS, Lecker SH \& Jagoe RT. Proteolysis in illness-associated skeletal muscle atrophy: from pathways to networks. Critical Reviews in Clinical Laboratory Sciences 201148 49-70. (doi:10.3109/10408363. 2011.586171)

11 Pires-Oliveira M, Maragno AL, Parreiras-e-Silva LT, Chiavegatti T, Gomes MD \& Godinho RO. Testosterone represses ubiquitin ligases atrogin-1 and Murf-1 expression in an androgen-sensitive rat skeletal muscle in vivo. Journal of Applied Physiology 2010108 266-273. (doi:10.1152/japplphysiol.00490.2009)

12 Parise G, Brose AN \& Tarnopolsky MA. Resistance exercise training decreases oxidative damage to DNA and increases cytochrome oxidase activity in older adults. Experimental Gerontology 200540 173-180. (doi:10.1016/j.exger.2004.09.002)

13 Williams AD, Carey MF, Selig S, Hayes A, Krum H, Patterson J, Toia D \& Hare DL. Circuit resistance training in chronic heart failure improves skeletal muscle mitochondrial ATP production rate - a randomized controlled trial. Journal of Cardiac Failure 200713 79-85. (doi:10.1016/j.cardfail.2006.10.017)
14 Hartl FU. Molecular chaperones in cellular protein folding. Nature 1996381 571-579.

15 Hightower LE. Heat shock, stress proteins, chaperones, and proteotoxicity. Cell 199166 191-197.

16 Paulsen G, Hanssen KE, Ronnestad BR, Kvamme NH, Ugelstad I, Kadi F \& Raastad T. Strength training elevates HSP27, HSP70 and alphaB-crystallin levels in musculi vastus lateralis and trapezius. European Journal of Applied Physiology 2012112 1773-1782.

17 Sun Y \& MacRae TH. Small heat shock proteins: molecular structure and chaperone function. Cellular and Molecular Life Sciences: CMLS 200562 2460-2476.

18 Carmeli E, Kodesh E \& Nemcovsky C. Tetracycline therapy for muscle atrophy due to immobilization. Journal of Musculoskeletal \& Neuronal Interactions 20099 81-88.

19 Setsuie R, Suzuki M, Tsuchiya Y \& Wada K. Skeletal muscles of Uchl3 knockout mice show polyubiquitinated protein accumulation and stress responses. Neurochemistry International 201056 911-918. (doi:10.1016/j.neuint.2010.03.021)

20 Cobley JN, Sakellariou GK, Owens DJ, Murray S, Waldron S, Gregson W, Fraser WD, Burniston JG, Iwanejko LA, McArdle A, et al. Lifelong training preserves some redox-regulated adaptive responses after an acute exercise stimulus in aged human skeletal muscle. Free Radical Biology \& Medicine 201470 23-32.

21 Noble EG, Milne KJ \& Melling CW. Heat shock proteins and exercise: a primer. Applied Physiology, Nutrition, and Metabolism 200833 1050-1065.

22 Thorsen L, Nilsen TS, Raastad T, Courneya KS, Skovlund E \& Fossa SD. A randomized controlled trial on the effectiveness of strength training on clinical and muscle cellular outcomes in patients with prostate cancer during androgen deprivation therapy: rationale and design. BMC Cancer 201212 123. (doi:10.1186/14712407-12-123)

23 Murphy JL, Blakely EL, Schaefer AM, He L, Wyrick P, Haller RG, Taylor RW, Turnbull DM \& Taivassalo T. Resistance training in patients with single, large-scale deletions of mitochondrial DNA. Brain: A Journal of Neurology $20081312832-2840$.

24 Weibel ER, Taylor CR \& Hoppeler H. The concept of symmorphosis: a testable hypothesis of structure-function relationship. PNAS 1991 88 10357-10361. (doi:10.1073/pnas.88.22.10357)

25 Rasmussen UF, Rasmussen HN, Krustrup P, Quistorff B, Saltin B \& Bangsbo J. Aerobic metabolism of human quadriceps muscle: in vivo data parallel measurements on isolated mitochondria. American Journal of Physiology: Endocrinology and Metabolism 2001280 E301-E307.

26 Betik AC, Thomas MM, Wright KJ, Riel CD \& Hepple RT. Exercise training from late middle age until senescence does not attenuate the declines in skeletal muscle aerobic function. American Journal of Physiology: Regulatory, Integrative and Comparative Physiology 2009297 R744-R755.

27 Hood MS, Little JP, Tarnopolsky MA, Myslik F \& Gibala MJ. Lowvolume interval training improves muscle oxidative capacity in sedentary adults. Medicine \& Science in Sports \& Exercise 201143 1849-1856.

28 Nilsen TS, Thorsen L, Fossa SD, Wiig M, Kirkegaard C, Skovlund E Benestad HB \& Raastad T. Effects of strength training on muscle cellular outcomes in prostate cancer patients on androgen deprivation therapy. Scandinavian Journal of Medicine \& Science in Sports 2015 [in press]. (doi:10.1111/sms.12543)

29 Conley KE, Amara CE, Jubrias SA \& Marcinek DJ. Mitochondrial function, fibre types and ageing: new insights from human muscle in vivo. Experimental Physiology 200792 333-339. (doi:10.1113/ expphysiol.2006.034330)

30 Liu Y, Lormes W, Baur C, Opitz-Gress A, Altenburg D, Lehmann M \& Steinacker JM. Human skeletal muscle HSP70 response to physical training depends on exercise intensity. International Journal of Sports Medicine 200021 351-355.

31 Gjovaag TF \& Dahl HA. Effect of training and detraining on the expression of heat shock proteins in $\mathrm{m}$. triceps brachii of untrained

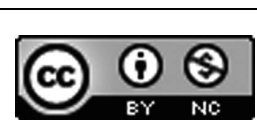

This work is licensed under a Creative Commons Attribution-NonCommercial 4.0 International License. 
males and females. European Journal of Applied Physiology $2006 \mathbf{9 8}$ 310-322. (doi:10.1007/s00421-006-0281-y)

32 Siu PM, Pistilli EE \& Alway SE. Apoptotic responses to hindlimb suspension in gastrocnemius muscles from young adult and aged rats. American Journal of Physiology: Regulatory, Integrative and Comparative Physiology 2005289 R1015-R1026.

33 Milne KJ, Thorp DB, Melling CW \& Noble EG. Castration inhibits exercise-induced accumulation of Hsp70 in male rodent hearts. American Journal of Physiology: Heart and Circulatory Physiology 2006 $290 \mathrm{H} 1610-\mathrm{H} 1616$.
34 Gonzalez B, Hernando R \& Manso R. Anabolic steroid and gender-dependent modulation of cytosolic HSP70s in fast- and slow-twitch skeletal muscle. Journal of Steroid Biochemistry and Molecular Biology 200074 63-71. (doi:10.1016/S09600760(00)00089-3)

35 Cunha TF, Bacurau AV, Moreira JB, Paixao NA, Campos JC, Ferreira JC, Leal ML, Negrao CE, Moriscot AS, Wisloff U, et al. Exercise training prevents oxidative stress and ubiquitin-proteasome system overactivity and reverse skeletal muscle atrophy in heart failure. PloS ONE 20127 e41701.

Received in final form 23 February 2016

Accepted 29 February 2016
This work is licensed under a Creative Commons Attribution-NonCommercial 4.0 International License. 